\title{
The Prevalence of Root Fractures among Patients Visiting a Specialised Tertiary Care Dental Care Clinic
}

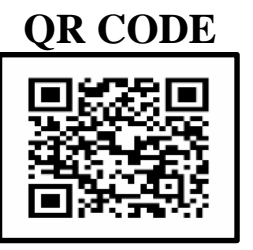

\section{SAVITA SHARMA1, ABHEY CHOWDHRY²}

INTRODUCTION: Following endodontic therapy, the development of root fracture(s) is considered to be a risk factor. It can be diagnosed accurately with the help of various radiographic aids.

AIM: To assess the prevalence of horizontal and vertical root fractures among endodontically treated teeth among patients visiting a specialised tertiary care dental care clinic.

METHODOLOGY: Patients suspected of having root fracture (due to endodontic treatment or non-endodontic treatment) were confirmed with the help of radiographic aids (IOPAR, OPG and occlusal radiographs). Root fractures due to endodontic treatment were then classified as horizontal and vertical root factures and analysed using the student's t-test, ANOVA and odd's ratio (OR). Data was analysed using SPSS version 21.0

RESULTS: The study population comprised of 383 subjects. Males (207, 54\%) formed a majority of the study population. Majority of fractures were seen in females $[(162,58.5 \%)$, endodontically treated teeth], while a slightly increased prevalence was seen among males $(92,86.8 \%)$ in non-endodontically treated teeth. A total of $277(72.3 \%)$ teeth were endodontically treated [155(55.9\%) horizontal and $122(44.1 \%)$ vertical fracture], while $106(27.7 \%)$ were 155 non-endodontically treated teeth [63(59.4\%) horizontal and $43(40.6 \%)$ vertical fracture]. A significance difference between horizontal and vertical root fractures [p=.005(t-test), $\mathrm{p}=.0025$ (ANOVA)] was seen. Odd's ratio analysis revealed that horizontal fractures $(\mathrm{OR}=\mathbf{2 . 2}$ ) were more prone to develop as compared to vertical fractures.

CONCLUSION: Owing to the fact that endodontically treated teeth are more brittle as compared to non-endodontically treated teeth, it is advised that the dental clinician should closely routinely follow- up endodontically treated teeth for signs of root fracture and confirm with a radiographical aid when such fractures are suspected.

KEYWORDS: Horizontal, Vertical, Root, Fracture, Endodontically, Teeth

\section{INTRODUCTION}

The treatment and retention of an endodontically treated tooth is a challenging aspect for dental clinicians worldwide. Owing to advances in the field of endodontics, a significant increase in the retention of endodontically treated teeth has been observed. However, their retention is considered an uphill task for the clinician as these teeth are often considered brittle and hence, calls for continuous care and follow up of the concerned tooth, which often challenges the skill and ingenuity of dental clinicians. ${ }^{1}$ In today's scenario, there is still a lack of consensus regarding the clinical procedures and materials to be used to restore teeth in endodontic procedures. Every treatment modality has its own advantages, disadvantages and complications. ${ }^{2}$

One of the major complications following teeth that are endodontically treated is the incidence of root fracture (RF) which leads to either root amputation (hemisectioning) or tooth extraction and causes discomfort to the patient along with unnecessary, expensive and increased dental visits. ${ }^{3}$ Fractures of root can be broadly classified into two categories: horizontal and vertical. They are further sub-defined as fractures involving the dentine, cementum and pulp. ${ }^{4}$ The prevalence of these fracture varies from 0.5 to $7 \%$ among the permanent dentition with the age group of 11 to 20 years being the most commonly affected population..$^{5-7}$

Among root fractures, the commonest form of root fracture is horizontal root fracture (seen primarily in the anterior maxillary teeth).., 8 Research shows that these types of fractures frequently occur at middle-third segment and are infrequently seen in the apical and coronal-third of the root structure. ${ }^{8}$ On the contrary, vertical root fractures are rare in nature, and extend through the long axis of the root toward the apex with prevalence ranging from 2 to $20 \%$. Sometimes these fractures are asymptomatic in nature and are only diagnosed during routine clinical, diagnostic procedures. ${ }^{9}$

Owing to the complex presentation of root fractures, additional diagnostic aids like IOPAR, 
occlusal radiographs, OPG etc., are required for rehabilitation(functional and aesthetic) of the tooth following such fractures. The aim of the present study is to identify the prevalence of root fractures among patients visiting the OPD of a specialised tertiary care dental care clinic. This study can assist clinicians to understand the myriad spectrum of root fracture presentation and thereby help them formulate an adequate management strategy.

\section{METHODOLOGY}

The study was conducted from July 2016 to August 2017 among patients visiting the OPD of a specialised tertiary care dental care clinic and suspected of having root fractures. To confirm the same, and IOPA/ OPG / occlusal radiograph was taken and cases of root fractures as a result of endontically treated teeth and well as nonendodontically treated teeth were identified. Only those teeth which had a permanent restoration and were treated endodontically /restored for more than six months were included. Following patient consent, data regarding the type and location of the root fracture, diagnostic aid used was entered into a spreadsheet and was analysed using statistical methods. The entire study protocol was approved from the Institutional Review Board (IRB) prior to commencement of the study. The statistical tests used were student's t-test, ANOVA (for-inter group comparison) and calculation of odd's ratio (OR). The data was analysed using SPSS version $21.0^{10}$ and $p$ value was set as significant when $\mathrm{p}$ value was $\leq 0.05$.

\section{RESULTS}

The study population comprised of 383 subjects and it was observed that males $(207,54 \%)$ formed a majority of the study population as compared to females $(176,46 \%)$. Table 1 describes the genderwise distribution of root fractures in both endodontically treated and non-endodontically treated teeth. It was seen that a majority of fractures among endodontically treated teeth were seen in females $(162,58.5 \%)$ while a higher prevalence was seen among males $(92,86.8 \%)$ in fractures related to non-endodontically treated teeth.

The types of fractures seen among both endodontically (with restoration) and nonendodontically treated teeth (with restoration) is shown in Table 2. Of the total of 383 fractured teeth examined, $277(72.3 \%)$ teeth were endodontically treated [155(55.9\%) horizontal and $122(44.1 \%)$ vertical fracture], while 106(27.7\%) were 155 non-endodontically treated teeth [63(59.4\%) horizontal and 43(40.6\%) vertical fracture] which fractured due to any other reason.

Table 3 describes the types of horizontal and vertical fracture(s) seen among endodontically (with restoration) treated teeth. It was observed that there were 155 teeth with horizontal fractures and a majority of them had single fracture (63, 40.6\%) followed by displaced fractures. Among vertical fractures, the majority comprised of complete fractures $(48,39.3 \%)$ followed by incomplete fractures $(32,26.2 \%)$ and supraosseous fractures (29, 23.7\%). Statistical analysis revealed a significance difference between horizontal and vertical root fractures $[\mathrm{p}=.005(\mathrm{t}-$ test), $\mathrm{p}=.0025$ (ANOVA)]. Odd's ratio analysis revealed that horizontal fractures $(\mathrm{OR}=2.2)$ were more prone to develop as compared to vertical fractures.

\section{DISCUSSION}

Diagnosis of root fractures (both horizontal and vertical) poses a clinical dilemma as the condition is often misdiagnosed as a periodontal disease or associated with endodontic lesions. Owing to the nature of the condition and in the absence of radiographic confirmatory tests, it is possible that many teeth with root fractures are simply extracted, especially among non-endodontically treated teeth. ${ }^{11,12}$

The present study identifies the prevalence of root fractures among patients visiting a specialised tertiary care dental care clinic using radiographic diagnostic procedures and found a total 383 patients suffering from different types of root fractures over a period of 13 months. The treatment protocol for root fractures varies and depends upon the location of root fracture: fractures in the apical third primarily needs a "watch and observe" protocol and if the pulp is vital, the segment can be retained, while if the pulp shows signs of necrosis, surgical extraction is advised. Fractures in the middle third can be managed through reduction and stabilization of the tooth. Approximately $75 \%$ of these fractures heal, and if the fracture does not heal and the pulp 
is necrosed, extraction is advised. Cervical fractures, have the poorest healing ability, and treatment protocols include reduction and stabilization, reattachment, periodontal surgery, orthodontic extrusion and finally if nothing works, surgical extraction. For vertical root fractures, extraction is advised in a single rooted tooth while multi-rooted teeth have been treated by uniting the fragments (through GIC, 4 META, dual cure resin cements, fibre posts with composite resin cores) and then replanting the tooth back in its socket. ${ }^{13-16}$ In both horizontal and vertical root fractures, long term follow up is required and is advised at 4 weeks, 6-8 weeks, 4 months, 6 months, 1 year and 5 years intervals. ${ }^{5}$

In the present study, the prevalence of horizontal root fractures was seen as $40.4 \%$. This percentage is higher as compared to Karhade et al. who reported a prevalence of $0.5-7 \%$ horizontal root fractures among all traumatic dental injuries. ${ }^{17}$ However, the prevalence calculated in the present study is only based on the total prevalence of fractured teeth and individual comparisons may vary from author to author. Similarly, the prevalence of vertical root fracture was seen as $31.8 \%$ and is higher in comparison to Zadik et al. ${ }^{18}$ $(8.8 \%)$ and Hansen et al (4\%). ${ }^{19}$ The results of the present study are however in agreement with Sjögren et al. who found the prevalence of vertical root fractures in endodontically treated as $30.8 \% .^{20}$ Such variations in the prevalence rates can be attributed to difference in author interpretation of vertical root fractures and also due to improper processing of radiographs. Additionally Garcia-Guerrero $C$ et al. stated that endodontic retreatment could be considered as a risk factor for the development of vertical root fracture after 1-8 years and additionally explains the high prevalence of root fractures in the present study. ${ }^{9}$

\section{CONCLUSION}

Due to loss of structural integrity, endodontically treated teeth need to be followed up routinely as they are predisposed for root fractures. If a root fracture is diagnosed, it should be treated promptly in order to optimise patient outcomes.

\section{REFERENCES}

1. Milot P, Stein RS. Root fracture in endodontically treated teeth related to post selection and crown design. The Journal of Prosthetic dentistry 1992; 68(3):428-35.

2. Faria ACL, Rodrigues RCS, de Almeida Antunes RP, de Mattos MDGC, Ribeiro RF. Endodontically treated teeth: Characteristics and considerations to restore them. Journal of Prosthodontic Research 2011; 55:69-74.

3. Llena-Puy MC, Forner-Navarro L, BarberoNavarro I. Vertical root fracture in endodontically treated teeth: A review of 25 cases. Oral Surg Oral Med Oral Pathol Oral Radiol Endod 2001; 92:5535.

4. Andreasen FM, Andreasen JO, Cvek M. Root fractures. In: Textbook and Color Atlas of Traumatic Injuries to Teeth. Andreasen FM, Andreasen JO, eds. Copenhagen:Blackwell Publishing Ltd, 2007:337-71.

5. Malhotra N, Kundabala M, Acharya S. A review of root fractures: Diagnosis, treatment and prognosis. Dent Update 2011; 38:615-28.

6. Majorana A, Pasini S, Bardellini E, Keller E. Clinical and epidemiological study of traumatic root fractures. Dent Traumatol 2002; 18: 77-8o.

7. Yates JA. Root fractures in permanent teeth: a clinical review. Int Endod J 1992; 25: 150-57.

8. Hovland EJ. Horizontal root fractures: treatment repair. Dent Clin North Am 1992; 36: 509-25.

9. García-Guerrero C, Parra-Junco C, QuijanoGuauque S, Molano N, Pineda GA, Marín-Zuluaga DJ. Vertical root fractures in endodonticallytreated teeth: A retrospective analysis of possible risk factors. J Invest Clin Dent. 2017; oo:e12273.

10. IBM Corp. Released 2012. IBM SPSS Statistics for Windows, Version 21.o. Armonk, NY: IBM Corp.

11. Chan CP, Lin CP, Tseng SC, Jeng JH. Vertical root fracture in endodontically versus nonendodontically treated teeth. Oral Surg Oral Med Oral Pathol Oral Radiol Endod 1999; 87:5047 .

12. Lommel TJ, Meister F, Gerstein H. Alveolar bone loss associated with vertical root fractures. Oral Surg Oral Med Oral Pathol 1978; 45:909-19.

13. Grippo JO. Abfractions: A new classification of hard tissue lesions of teeth. J Esthet Dent. 1991; 1:14-9.

14. Harvey TE, White JT, Leeb IJ. Lateral condensation stress in root canals. J Endod. 1981; 7:151-5.

15. Hagiya YK, Yoshioka T, Suda H. Logistic regression equation to screen for vertical root 
fracture using periapical radiographs. Dentomaxillofac Radiol. 2008; 37:28-33.

16. Kajan ZD, Taromsari M. Value of cone beam computed tomography in the detection dental root fracture. Dentomaxillofac Radiol. 2012; 41:310

17. Karhade I, Gulve MN. Management of Horizontal Root Fracture in the Middle Third via Intraradicular Splinting Using a Fiber Post. Case Reports in Dentistry. 2016;:9684035.

Source of support: Nil, Conflict of interest: None declared
18. Zadik Y, Sandler V, Bechor R, Salehrabi R. Analysis of factors related to extraction of endodontically treated teeth. Oral Surg Oral Med Oral Pathol Oral Radiol Endod 2008; 106:31-5.

19. Hansen EK, Asmussen E, Christiansen N. In vivo fractures of endodontically treated posterior teeth restored with amalgam. Endod Dent Traumatol 1990; 6:49-55.

20. SjoĖgren U, HoĖgglund B, Sundqvist G, Wing K. Factors affecting long term results of endodontic treatment. J Endod 1990; 16:498-504.

AUTHOR AFFILIATIONS

BDS (Private Practitioner)

2. BDS (Private Practitioner)

\section{Corresponding Author: \\ Dr. Abhey Chowdhry \\ BDS (Private Practitioner) \\ Swami Vivekananda Charitable Dental \\ Hospital, Peer Muchalla, Zirakpur \\ Punjab.}

For manuscript enquiry/author contact details, e-mail at:

maunscriptenquiry.ihrj@gmail.com

\section{LEGENDS}

\begin{tabular}{|c|c|c|}
\hline CHARACTRISTIC & GENDER & $\mathbf{n}(\%)$ \\
\hline $\begin{array}{c}\text { Endodontically } \\
\text { treated teeth }\end{array}$ & Males & $115(41.5 \%)$ \\
\hline & females & $162(58.5 \%)$ \\
\hline $\begin{array}{c}\text { Non- } \\
\text { Endodontically } \\
\text { treated teeth }\end{array}$ & Males & $\mathbf{2 7 7}(\mathbf{1 0 0} \%)$ \\
\hline & Total & $92(86.8 \%)$ \\
\hline & Total & $88(13.2 \%)$ \\
\hline
\end{tabular}

Table 1. Gender-wise distribution fractures in in both endodontically treated and nonendodontically treated teeth 


\begin{tabular}{|cccc|}
\hline $\begin{array}{c}\text { TOTAL NO. } \\
\text { OF }\end{array}$ & $\begin{array}{c}\text { EDODONTICALLY } \\
\text { TREATED TEETH }\end{array}$ & $\begin{array}{c}\text { NON- } \\
\text { ENDODONTICALLY }\end{array}$ & TOTAL \\
FRACTURES & $\begin{array}{c}\text { WITH } \\
\text { TREATED TEETH }\end{array}$ & \\
\hline $\begin{array}{c}\text { Horizontal } \\
\text { root fracture }\end{array}$ & $\mathbf{1 5 5}(55.9 \%)$ & $63(59.4 \%)$ & $\mathbf{2 1 8}(56.9 \%)$ \\
\hline $\begin{array}{c}\text { Vertical root } \\
\text { fracture }\end{array}$ & $\mathbf{1 2 2}(44.1)$ & $43(40.6 \%)$ & $\mathbf{1 6 5}(43.1 \%)$ \\
\hline Total & $\mathbf{2 7 7}(\mathbf{7 2 . 3} \%)$ & $\mathbf{1 0 6}(\mathbf{2 7 . 7} \%)$ & $\mathbf{3 8 3}(\mathbf{1 0 0} \%)$ \\
\hline
\end{tabular}

Table 2. Types of fracture(s) i.e horizontal and vertical seen among both endodontically (with restoration) and non-endodontically treated teeth(with restoration

\begin{tabular}{|c|c|c|c|c|}
\hline \multicolumn{3}{|c|}{ CHARACTERISTIC } & $\mathrm{N}(\%)$ & \\
\hline \multirow{8}{*}{$\begin{array}{l}\text { Horizontal } \\
\text { fractures }\end{array}$} & \multirow[t]{2}{*}{ Number } & Single & $63(40.6 \%)$ & \multirow{3}{*}{$\begin{array}{c}\text { Horizontal } \\
\text { fracture }^{*} \text { vertical } \\
\text { fracture }\end{array}$} \\
\hline & & Multiple & $10(6.4 \%)$ & \\
\hline & \multirow[t]{3}{*}{ Location } & Cervical & $21(13.5 \%)$ & \\
\hline & & Middle & $18(11.6 \%)$ & \multirow{4}{*}{$\begin{array}{c}\mathrm{p}=0.005^{*}(\mathrm{Chi} \\
\text { Squared })\end{array}$} \\
\hline & & Apical & 03(1.9\%) & \\
\hline & \multirow{2}{*}{$\begin{array}{c}\text { Position of } \\
\text { Coronal } \\
\text { fragment }\end{array}$} & Not displaced & $16(10.3 \%)$ & \\
\hline & & displaced & $24(15 \cdot 7 \%)$ & \\
\hline & \multicolumn{2}{|c|}{ Total } & $155(100 \%)$ & $\mathrm{p}=0.025^{*}(\mathrm{ANOVA})$ \\
\hline \multirow{6}{*}{$\begin{array}{l}\text { Vertical } \\
\text { Fractures }\end{array}$} & \multirow{2}{*}{$\begin{array}{c}\text { Fragment } \\
\text { separation }\end{array}$} & Complete & $48(39 \cdot 3 \%)$ & \multirow{6}{*}{$\begin{array}{c}\mathrm{OR}=\mathbf{2 . 2} \text { (Horizontal } \\
\text { fractures vs Vertical } \\
\text { fractures) }\end{array}$} \\
\hline & & Incomplete & $32(26.2 \%)$ & \\
\hline & \multirow{2}{*}{$\begin{array}{l}\text { Fracture } \\
\text { position }\end{array}$} & Supra-osseous & $29(23.7 \%)$ & \\
\hline & & Intra-osseous & $13(10.8 \%)$ & \\
\hline & \multicolumn{2}{|c|}{ Total } & $122(100 \%)$ & \\
\hline & \multicolumn{2}{|c|}{ Total } & $277(100 \%)$ & \\
\hline
\end{tabular}

Table 3. Types of horizontal and vertical fracture(s) seen among endodontically treated teeth (with restoration) 